\title{
The Assimilation of 2-C Compounds other than Acetate
}

\author{
By J. G. MORRIS \\ Department of Biochemistry, University of Leicester, Leicester
}

The tricarboxylic acid cycle is both the main terminal respiratory pathway in micro-organisms and a source of precursors for the net biosynthesis of cell constituents. Intermediates drained away from the cycle for these biosynthetic purposes must be replenished; a process accomplished by carboxylation reactions when suitable $\mathrm{CO}_{2}$-acceptor molecules (e.g. pyruvate and phosphopyruvate) are available. Any organism that utilizes a 2-C compound as sole source of carbon for growth must therefore be endowed with a means of forming from this substrate either the TCA cycle intermediates themselves or such 3-C $\mathrm{CO}_{2}$-acceptors.

The glyoxylate cycle (Kornberg \& Krebs, 1957; Kornberg \& Madsen, 1958) in which isocitrate lyase (Smith \& Gunsalus, 1954; Olson, 1954) and malate synthase (Wong \& Ajl, 1956) operate in conjunction with enzymes of the TCA cycle to form 1 mol. unit of succinate from 2 mol. units of acetate, is the best documented of all such pathways. However, this biosynthetic route is not available to organisms utilizing 2-C compounds more highly oxidized than acetate. A number of pathways all involving glyoxylate or glycine or both have now been described whereby net synthesis of pyruvate from such compounds may be accomplished.

In micro-organisms such as Escherichia coli or Pseudomonas growing on glycollate, the necessary net formation of TCA cycle intermediates is effected via the 'glycerate pathway' (Kornberg, 1961). In this pathway glyoxylate (derived from the oxidation of the glycollate) undergoes a condensation reaction in which 2 mol. units of glyoxylate yield 1 mol. unit each of tartronic semialdehyde and carbon dioxide (Krakow \& Barkulis, 1956; Krakow, Barkulis \& Hayashi, 1961; Kornberg \& Gotto, $1959,1961)$ : the enzyme catalysing this process has been named glyoxylic carboligase (Krakow, Barkulis \& Hayashi, 1961). The tartronic semialdehyde thus formed is subsequently reduced to glyceric acid by tartronic semialdehyde reductase (Kornberg \& Gotto, 1959, 1961; Krakow, Udaka \& Vennesland, 1962). In the presence of ATP and Pseudomonas extracts, glyceric acid has been shown to yield pyruvate, presumably via the well-established Embden-Meyerhof sequence. The net effect of these reactions is to transform 2 mol. units of glycollate to 1 mol. unit of carbon dioxide and one of pyruvate which can either be carboxylated to oxaloacetate, or, after oxidation to acetylcoenzyme $\mathbf{A}$, condensed with a third mol. unit of glyoxylate to yield malate (Kornberg \& Sadler, 1961); in either case, the de novo formation of intermediates of the TCA cycle from glycollate has been effected.

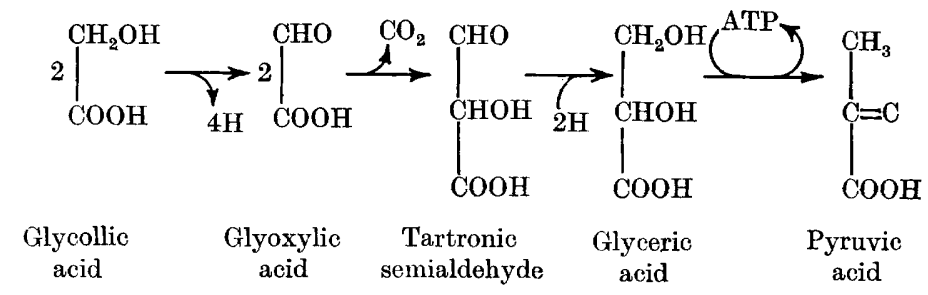


The glycerate pathway operates not only during growth on glycollate but also on a number of 2-C compounds that first give rise to glyoxylate. Thus Callely \& Dagley (1959) reported that glyoxylic acid carboligase and tartronic semialdehyde reductase were present in large amounts in extracts of a pseudomonad grown on glycine. Pseudomonas oxalaticus also formed these enzymes during growth on oxalate; this provided evidence for the initial reduction of oxalate to glyoxylate by this organism (Quayle \& Keech, 1959). In this process oxalate is activated to oxalylcoenzyme A (Quayle, Keech \& Taylor, 1961) which is reduced to glyoxylate by glyoxylic dehydrogenase and $\mathrm{NADPH}_{2}$ (Quayle \& Taylor, 1961). Thus pseudomonads growing on glycollate, glycine or oxalate are all in effect growing on glyoxylate and a source of 'reducing power'.

It is probable that in some organisms an alternative route for glycine utilization is available which does not require its preliminary deamination. Kornberg \& Morris (unpublished) observed that serine, alanine and glutamate were early-labelled products during growth of Arthrobacter globiformis on $\left[{ }^{14} \mathrm{C}\right]$-glycine. Extracts of the organism formed pyruvate, alanine and $\mathrm{CO}_{2}$ from glycine in the presence of reduced pyridine nucleotides, pyridoxal phosphate and tetrahydrofolic acid. It would seem that in such coryneform organisms 2 mol. units of glycine might undergo a condensative decarboxylation in the presence of pyridoxal phosphate and a folic acid derivative to give serine, which would readily yield pyruvate through the action of serine dehydratase. This reaction sequence has been convincingly demonstrated in anaerobic organisms capable of fermenting glycine with acetate as end product, e.g. Clostridium acidi-urici (Radin \& Barker, 1953; Sagers \& Beck, 1956), Diplococcus glycinophilus (Barker, Volcani \& Cardon, 1948; Sagers \& Gunsalus, 1961). A similar route may be used for the metabolism of glycollate in plants (Rabson, Tolbert \& Kearney, 1962).

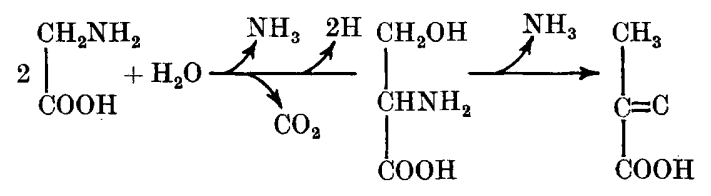

Glycine Serine Pyruvic acid

Here, as in the glycerate pathway, 2 mol. units of the 2 -C substrate undergo a condensation reaction wherein one $3-\mathrm{C}$ product is formed with the loss of the carbon atom derived from one carboxyl group as carbon dioxide.

A novel metabolic route which avoids this loss of $\mathrm{CO}_{2}$ in the initial formation of a compound containing more than 2 ćarbon atoms operates during growth of Micrococcus denitrificans on substrates catabolized to glyoxylate. Here both glycine and glyoxylate are required for the nett formation of TCA cycle intermediates. When $M$. denitrificans was grown on glycollate as sole carbon source, no glyoxylic carboligase activity was present despite initial oxidation of the substrate to form glyoxylate. Short-term incubation of growing cultures with $\left[1-{ }^{14} \mathrm{C}\right]$-glycollate resulted in the appearance of isotope first in glycine, malate and aspartate. In contrast to the results obtained with Pseudomonas and Escherichia coli, no isotope was detected in glycerate or phosphoglycerate. Evidence was obtained that during growth on glycollate two hitherto unreported enzymes were inducibly formed by $\boldsymbol{M}$. denitri- 
ficans $(a)$ an aldolase-type enzyme which catalysed the condensation of glycine and glyoxylate to form erythro- $\beta$-hydroxyaspartate, and $(b)$ a $\beta$-hydroxyaspartate dehydratase capable of forming oxaloacetate from the erythro form of $\beta$-hydroxyaspartate (Kornberg \& Morris, $1962 a, b$ ). Acting in conjunction with a mechanism for the production of glycine from glyoxylate these enzymes could account for the formation of $1 \mathrm{~mol}$. unit of a 4-C compound (oxaloacetate) from 2 mol. units of glyoxylate without concomitant loss of $\mathrm{CO}_{2}$ (though the subsequent utilization of oxaloacetate for biosyntheses would, of course, be accompanied by loss of $\mathrm{CO}_{2}$ (Kornberg \& Morris, 1963).

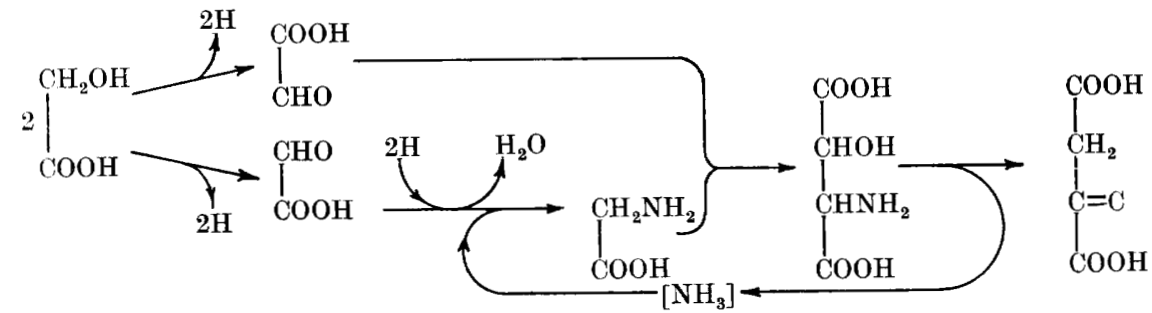

$$
\begin{array}{ccccc}
\text { Glycollic } & \text { Glyoxylic } & \text { Glycine } & \beta \text {-Hydroxyaspartic } & \text { Oxaloacetic } \\
\text { acid } & \text { acid } & \text { acid }
\end{array}
$$

Other sources of glyoxylate, e.g. allantoin and ethyleneglycol, are also utilized by Micrococcus denitrificans via this $\beta$-hydroxyaspartate pathway.

\section{REFERENCES}

Barker, H. A., Volcani, B. E. \& Cardon, B. P. (1948). Tracer experiments on the mechanism of glycine fermentation by Diplococcus glycinophilus. J. biol. Chem. 173, 803.

Callely, A. C. \& Dagley, S. (1959). Metabolism of glycine by a pseudomonad. Nature, Lond. 183, 1793.

Kornberg, H. I. (1961). Selective utilisation of metabolic routes by Escherichia coli. Cold Spr. Harb. Symp. quant. Biol. 26, 257-60.

Kornberg, H. L. \& Gotro, A. M. (1959). Formation of malate from glycollate by Pseudomonas ovalis Chester. Nature, Lond. 183, 1791.

Kornberg, H. L. \& Gotro, A. M. (1961). The metabolism of $\mathbf{C}_{2}$-compounds in microorganisms. 6. Synthesis of cell constituents from glycollate by Pseudomonas sp. Biochem. J. 78, 69.

Konnberg, H. L. \& Krebs, H. A. (1957). Synthesis of cell constituents from $\mathrm{C}_{2}$-units by a modified tricarboxylic acid cycle. Nature, Lond. 179, 988.

Kornberg, H. L. \& Madsen, N. B. (1958). The metabolism of $\mathbf{C}_{2}$-compounds in microorganisms. 3. Synthesis of malate from acetate via the glyoxylate cycle. Biochem. J. 68,549 .

Kornberg, H. L. \& Morris, J. G. (1962a). Enzymic formation of oxaloacetate from erythro- $\beta$-hydroxyaspartate. Biochim. biophys. Acta, 65, 537.

KornBerg, H. L. \& Morris, J. G. (1962b). The influence of growth substrates on oxaloacetate formation from $\beta$-hydroxyaspartate by Micrococcus denitrificans. Biochim. biophys. Acta, 65, 378.

Kornberg, H. L. \& Morris, J. G. (1963). The $\beta$-hydroxyaspartate pathway: a new route for biosyntheses from glyoxylate. Nature, Lond. 197, 456.

Kornberg, H. L. \& SADler, J. R. (1961). The metabolism of $\mathrm{C}_{2}$-compounds in microorganisms. 8. A dicarboxylic acid cycle as a route for the oxidation of glycollate by Escherichia coli. Biochem. J. 81, 503. 
Krakow, C. \& Barkulis, S. S. (1956). Conversion of glyoxylate to hydroxypyruvate by extracts of Escherichia coli. Biochim. biophys. Acta, $21,593$.

Krakow, G., Barkulis, S. S. \& HaYashi, J. A. (1961). Glyoxylic acid carboligase: an enzyme present in glycollate-grown Escherichia coli. J. Bact. 81, 509.

Krakow, G., UdAKa, S. \& Vennesland, B. (1962). The stereochemistry of the reaction catalysed by D-glyceric-3-dehydrogenase. Biochemistry, 1, 254.

OLson, J. A. (1954). The D-isocitric lyase system: the formation of glyoxylic and succinic acids from D-isocitric acid. Nature, Lond. 174, 695.

QuAyle, J. R. \& KEEch, D. B. (1959). Formation of glycerate from oxalate by Pseudomonas oxaliticus (ox 1) grown in oxalate. Nature, Lond. 183, 1794.

QuaYle, J. R., KeECh, D. B. \& TAYlor, G. A. (1961). Metabolism of oxalate in cell-free extracts of the organism grown on oxalate. Biochem. J. 78, 225.

Quayle, J. R. \& TaYlor, G. A. (1961). Purification and properties of glyoxylic dehydrogenase. Biochem. $J .78,611$.

Rabson, R., Tolbert, N. E. \& Kearney, P. C. (1962). Formation of serine and glyceric acid by the glycollate pathway. Arch. Biochem. 98, 154.

Radin, N. S. \& Barker, H. A. (1953). Enzymic reactions in purine decomposition by preparations of Clostridium acidi-urici. Proc. nat. Acad. Sci. Wash. 39, 1196.

SAGERS, R. D. \& BECK, J. V. (1956). Studies on the formation of formate, glycine, serine, pyruvate and acetate from purines by Clostridium acidi-urici. J. Bact. 72, 199 .

Sagers, R. D. \& Gunsalus, I. C. (1961). Intermediary metabolism of Diplococcus glycinophilus. 1. Glycine cleavage and one-carbon interconversions. J. Bact. 81, 541.

Smith, R. A. \& Gunsalus, I. C. (1954). Isocitrase; a new tricarboxylic acid cleavage system. J. Amer. chem. Soc. 76, 5002.

Wong, D. T. O. \& AJL, S. J. (1956). Conversion of acetate and glyoxylate to malate. J. Amer. chem. Soc. 78, 3230. 